\title{
Spatial contrast sensitivity in benign intracranial hypertension
}

\author{
C BULENS,* J D MEERWALDT, $\dagger$ P J KOUDSTAAL, $\dagger$ G J VAN DER WILDT $\ddagger$
}

\begin{abstract}
From the Department of Neurology, Sint Franciscus Gasthuis Rotterdam, * Department of Neurology of the Academic Hospital Dijkzigt Rotterdam, $\dagger$ and the Department of Biological and Medical Physics, Erasmus University, $\ddagger$ Rotterdam, The Netherlands
\end{abstract}

SUMMARY Spatial Contrast Sensitivity (CS) was studied in 20 patients with benign intracranial hypertension (BIH). At presentation CS loss was found in $43 \%$ of the eyes, and impairment of visual acuity attributed to BIH in only $16 \%$. Nine patients had blurred vision or visual obscurations, all of whom had abnormal CS. The clinical application of CS measurement in BIH for monitoring the progression or regression of the disease is illustrated by serial measurements in 11 patients. Progressive visual loss in longstanding papilloedema and improvement of visual function in subsiding papilloedema can occur without any change in Snellen acuity or visual field charting.

In benign intracranial hypertension (BIH), loss of visual acuity is the only serious complication, and may occur early or late in its course. ${ }^{1}$ Regular ophthalmological examination, including assessment of the visual fields, is mandatory. A major problem, however, is that there is no reliable warning sign of impending visual failure, which obstructs rational decision in treatment. ${ }^{2}$ Patients with papilloedema from whatever cause (tumour or benign intracranial hypertension) may present with transient visual obscurations or blurred vision. ${ }^{1-9}$ Optic nerve dysfunction caused by papilloedema can decrease central visual function, in spite of clinically normal visual acuity.

Subtle visual deficits may not be detected using routine tests, such as Snellen acuity scores, visual field estimation, or colour vision testing. Such patients might have a peculiar sort of visual disturbance, reducing central visual function, without affecting visual acuity. Because normal spatial vision implies the ability to see coarse spatial patterns as well as fine detail, acuity tests, as measured with the Snellen letters, provide only limited information about visual perception. For evaluating spatial vision, sensitivity measurements to visual contrast using stimuli ranging from low spatial frequencies (coarse patterns) to high spatial frequencies (fine patterns) can be determined.

Address for reprint requests: Dr C Bulens, Department of Neurology, Sint Franciscus Gasthuis, Kleiweg 500, 3045 PM Rotterdam, The Netherlands.

Received 15 January 1988 and in revised form 10 May 1988. Accepted 13 May 1988
The grating stimuli usually employed in visual studies are sinusoidal, where the luminance of alternating light and dark bars are varied in sinusoidal fashion; spatial frequency corresponds to the number of pairs of light and dark bars per degree of visual angle. The reason for using sinusoidal gratings is that mathematically these are the simplest of all possible patterns.

It has become obvious that with Contrast Sensitivity (CS) measurements one can detect visual loss which is not obtainable by conventional visual methods. This technique has been widely used to study visual dysfunction in various neuroophthalmological disorders. ${ }^{10}$ In the present study we investigate the effect of BIH on CS function.

\section{Subjects and methods}

\section{Subjects}

The control population of 20 subjects consisted of hospital personnel and patients without CNS disease. All had neuroophthalmological examinations and were free of ocular disease. Snellen acuities were $10 / 10$ or better.

Twenty patients were studied who complied with the definition of BIH: symptoms and signs of raised CSF pressure including papilloedema, without space occupying lesion, normal CSF under raised pressure, and normal ventricular size on CT. All had a complete neuroophthalmological examination which included measurements of corrected Snellen acuity, Goldmann perimetry, and Contrast Sensitivity.

\section{Methods}

Contrast Sensitivity Measurement

Our methods of CS measurements have been described else- 
where in detail. ${ }^{11}$ Briefly, the stimuli consisted of vertically orientated gratings with a sinusoidal luminance profile generated on a video monitor (Bosch, type M 38 BA 487 TA). Contrast was measured to be linear up to $100 \%$, for all spatial frequencies that were used. To avoid after images, the phase of the grating was alternated with a frequency of 0.8 $\mathrm{Hz}$. It is known that, in measurements using gratings consisting of less than four or five cycles, the CS is strongly dependent on the number of cycles presented. ${ }^{12-14}$ To realise that all gratings presented consisted of four or more cycles, it was not possible to measure CS for all spatial frequencies at one viewing distance. Therefore, the monitor was placed at a distance of $50 \mathrm{~cm}$ from the eye of the subject for spatial frequencies of 0.1 to $0.8 \mathrm{cycles} /$ degree (c/d). For the higher spatial frequencies $(0 \cdot 8-25 \cdot 6)$, the distance from the eye was automatically changed to $200 \mathrm{~cm}$ to compensate for limitations in the monitor system at high frequencies. The stimulus field subtended a visual angle of $32.5^{\circ}$ horizontally and $23.5^{\circ}$ vertically at $50 \mathrm{~cm}$ and $8.5^{\circ}$ and $6.0^{\circ}$, respectively, at $200 \mathrm{~cm}$. The mean luminance for all stimuli presented was $5 \mathrm{~cd} / \mathrm{m}^{2}$ at both viewing distances. The stimulus field was viewed in a dark surround. The contrast sensitivity for each spatial frequency was defined as the inverse of contrast threshold averaged over eight "reversal points". ${ }^{11}$ A plot of CS vs spatial frequency generated a spatial frequency contrast function.

\section{Results}

\section{Control group}

The mean age of the control group was 40 years (range, 26-59). The CS functions of the 40 control eyes were obtained and the mean CS curve is shown in fig 1. Close inspection of individual CS curves in normal subjects can reveal that at intermediate spatial frequencies a CS curve can diverge slightly from the

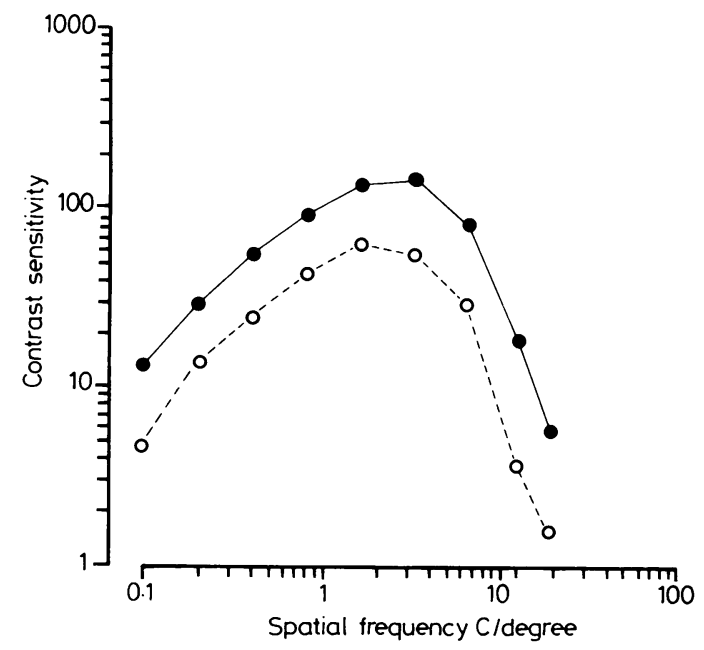

Fig 1 Mean contrast sensitivity curve in 20 normal subjects (filled circles). $-2 S D$ (open circles). pure inverted U shape (fig 1). These minor deflections occurred in 27 of the 40 normal eyes at different spatial frequencies (between 0.2 and $12.8 \mathrm{c} / \mathrm{d}$ ). The decrease factor (DF) of these minor deflections was defined as the ratio of the measured CS and the expected value of the non diverged individual curve for a given spatial frequency $(\log / \log )$. The mean decrease factor (DF) of these minor deflections was $1.20(2$ SD 0.22$)$, range: $1 \cdot 10$ at $6.4 \mathrm{c} / \mathrm{d}-1.29$ at 12.8 $\mathrm{c} / \mathrm{d}$, which is completely within intraindividual variability.

\section{Patients}

The mean age of the $20 \mathrm{BIH}$ patients was 39 years (range, 16-59). There were 16 females and four males. Eleven patients were obese and systemic hypertension (BP of 170/95 mm Hg or higher) was present in four. Papilloedema, the cardinal feature, was present in all patients and was confirmed by fluorescein angiography in eight cases. Neuroradiological investigations (skull radiographs and computed tomography) revealed that two patients had an empty sella. Carotid angiography, carried out in four males and two females, was normal in all. The increased CSF pressure ranged from 30 to $60 \mathrm{~cm}$ water (lumbar puncture).

Impairment of visual acuity was defined as Snellen acuity of less than 10/10. Nine patients had impairment of visual acuity (nine eyes). In three of these (patients 3,7,19) the poor visual acuity was unrelated to BIH (unilateral amblyopia since childhood). Five patients had mild impairment (7/10 or more), one patient had a marked degree of impairment of vision (3/10).

Visual fields were assessed by Goldmann perimetry in all patients. Only four showed abnormalities other than enlarged blind spots. One patient had severe concentric constrictions in both eyes. Another patient had a cecocentral scotoma with impaired visual acuity in one eye and a normal visual field with unimpaired visual acuity in the other. One patient had inferior binasal field defects with unilateral vision loss. The fourth patient had a unilateral inferior nasal field defect and normal acuity in both eyes.

The contrast sensitivity function of each of the patient's eyes was individually compared with the mean CS curves of the controls. A curve was judged abnormal when a CS deficit resulted in a displacement of (a part of) the curve below the control curve minus two standard deviations. Intermediate frequency loss was considered abnormal (notch defect) when the decrease factor (DF) was more than 1.42 , being the mean DF in 27 of the 40 normal eyes plus two standard deviations. The width of the notch was defined as the spatial frequency bandwidth over which con- 
Table 1 Results at presentation of neuro-ophthalmological investigations in 20 BIH patients

\begin{tabular}{|c|c|c|c|c|c|c|c|}
\hline No & Sex & Age (yr) & Vision & Snellen acuity & Papilloedema & Visual field & CS function \\
\hline 1 & $\mathbf{F}$ & 16 & Blurred & $\begin{array}{ll}\mathrm{R} & 11 / 10 \\
\mathrm{~L} & 10 / 10\end{array}$ & $\begin{array}{l}2 \\
2\end{array}$ & $\begin{array}{l}\text { Enl. blind spot } \\
\text { Enl. blind spot }\end{array}$ & $\begin{array}{l}\text { No loss } \\
\text { n loss } \\
(0 \cdot 4-3 \cdot 2)\end{array}$ \\
\hline 2 & $\mathbf{F}$ & 17 & Blurred & R $15 / 10$ & 2 & Enl. blind spot & $\begin{array}{l}n \text { loss } \\
(0 \cdot 8-2 \cdot 4)\end{array}$ \\
\hline 3 & $\mathbf{F}$ & 24 & Normal & $\begin{array}{l}\mathrm{L} \quad 10 / 10 \\
\mathrm{R} \quad 9 / 10 \\
\text { (amblyopic) }\end{array}$ & $\begin{array}{l}2 \\
2\end{array}$ & $\begin{array}{l}\text { Enl. blind spot } \\
\text { Enl. blind spot }\end{array}$ & $\begin{array}{l}\text { No loss } \\
\text { No loss }\end{array}$ \\
\hline 4 & $\mathbf{F}$ & 33 & Obscurations & $\begin{array}{ll}\text { L } & 10 / 10 \\
\text { R } & 12 / 10\end{array}$ & $\begin{array}{l}1 \\
2\end{array}$ & $\begin{array}{l}\text { Enl. blind spot } \\
\text { Enl. blind spot }\end{array}$ & $\begin{array}{l}\text { No loss } \\
\text { n loss } \\
(3 \cdot 2-12 \cdot 8)\end{array}$ \\
\hline & & & & L $\quad 15 / 10$ & 1 & Enl. blind spot & $\begin{array}{l}n \text { loss } \\
(0 \cdot 4-1 \cdot 6)\end{array}$ \\
\hline 5 & $\mathbf{F}$ & 34 & Blurred & $\begin{array}{ll}\mathrm{R} & 10 / 10 \\
\mathrm{~L} & 10 / 10\end{array}$ & $\begin{array}{l}1 \\
1\end{array}$ & $\begin{array}{l}\text { Severe concentric constriction } \\
\text { Severe concentric constriction }\end{array}$ & $\begin{array}{l}1 \text { loss } \\
1 \text { loss }\end{array}$ \\
\hline 6 & $\mathbf{M}$ & 34 & Normal & $\begin{array}{ll}\mathrm{R} & 15 / 10 \\
\mathrm{~L} & 15 / 10\end{array}$ & 1 & $\begin{array}{l}\text { Enl. blind spot } \\
\text { Enl. blind spot }\end{array}$ & $\begin{array}{l}\text { No loss } \\
\text { No loss }\end{array}$ \\
\hline 7 & $\mathbf{F}$ & 37 & Blurred & $\begin{array}{l}\mathrm{R} \\
\mathrm{L} \quad 7 / 10 \\
\text { (amblyopic) }\end{array}$ & 1 & $\begin{array}{l}\text { Enl. blind spot } \\
\text { Normal }\end{array}$ & $\begin{array}{l}\text { Generalised loss } \\
1 \text { loss }\end{array}$ \\
\hline 8 & $\mathbf{F}$ & 40 & Blurred & $\begin{array}{ll}\mathrm{R} \quad 10 / 10 \\
\mathrm{~L} & 3 / 10\end{array}$ & 1 & $\begin{array}{l}\text { Enl. blind spot } \\
\text { Enl. blind spot }\end{array}$ & $\begin{array}{l}\text { Generalised loss } \\
\text { Generalised loss }\end{array}$ \\
\hline 9 & $\mathbf{F}$ & 40 & Blurred & $\begin{array}{ll}\mathrm{R} & 10 / 10 \\
\mathrm{~L} & 10 / 10\end{array}$ & $\begin{array}{l}1 \\
2\end{array}$ & $\begin{array}{l}\text { Enl. blind spot } \\
\text { Enl. blind spot }\end{array}$ & $\begin{array}{l}\text { No loss } \\
\text { n loss } \\
(0 \cdot 2-0 \cdot 8)\end{array}$ \\
\hline 10 & $\mathbf{F}$ & 41 & Normal & $\begin{array}{ll}\mathrm{R} & 10 / 10 \\
\mathrm{~L} & 10 / 10\end{array}$ & 1 & $\begin{array}{l}\text { Enl. blind spot } \\
\text { Enl. blind spot }\end{array}$ & $\begin{array}{l}\text { No loss } \\
\text { No loss }\end{array}$ \\
\hline 11 & $\mathbf{F}$ & 41 & Normal & $\begin{array}{ll}\mathrm{R} & 10 / 10 \\
\mathrm{~L} & 10 / 10\end{array}$ & $\begin{array}{l}2 \\
1\end{array}$ & $\begin{array}{l}\text { Enl. blind spot } \\
\text { Enl. blind spot }\end{array}$ & $\begin{array}{l}\text { No loss } \\
\text { No loss }\end{array}$ \\
\hline 12 & $F$ & 42 & Blurred & R $10 / 10$ & 2 & Enl. blind spot & $\begin{array}{l}n \text { loss } \\
(0 \cdot 8-6 \cdot 4)\end{array}$ \\
\hline 13 & $\mathbf{M}$ & 43 & Obscurations & $\begin{array}{lr}\mathrm{L} & 10 / 10 \\
\mathrm{R} & 10 / 10 \\
\mathrm{~L} & 7 / 10\end{array}$ & $\begin{array}{l}2 \\
1 \\
2\end{array}$ & $\begin{array}{l}\text { Enl. blind spot } \\
\text { Normal } \\
\text { Cecocentral scotoma }\end{array}$ & $\begin{array}{l}\text { No loss } \\
\text { No loss } \\
\mathrm{n} \text { loss } \\
(1 \cdot 6-6 \cdot 4)\end{array}$ \\
\hline 14 & $\mathbf{F}$ & 46 & Normal & $\begin{array}{lr}\mathrm{R} & 11 / 10 \\
\mathrm{~L} & 9 / 10\end{array}$ & $\begin{array}{l}1 \\
1\end{array}$ & $\begin{array}{l}\text { Enl. blind spot } \\
\text { Enl. blind spot }\end{array}$ & $\begin{array}{l}\text { No loss } \\
\text { No loss }\end{array}$ \\
\hline 15 & $\mathbf{F}$ & 47 & Normal & $\begin{array}{ll}\mathrm{R} & 12 / 10 \\
\mathrm{~L} & 12 / 10\end{array}$ & $i$ & $\begin{array}{l}\text { Normal } \\
\text { Nasal defect }\end{array}$ & $\begin{array}{l}\text { No loss } \\
\text { No loss }\end{array}$ \\
\hline 16 & $\mathbf{F}$ & 49 & Obscurations & $\begin{array}{lr}\mathrm{R} & 10 / 10 \\
\mathrm{~L} & 8 / 10\end{array}$ & 1 & $\begin{array}{l}\text { Enl. blind spot and nasal defect } \\
\text { Enl. blind spot and nasal defect }\end{array}$ & $\begin{array}{l}\text { No loss } \\
\text { n loss } \\
(0 \cdot 8-3 \cdot 2)\end{array}$ \\
\hline 17 & $\mathbf{F}$ & 51 & Obscurations & $\begin{array}{lr}R & 11 / 10 \\
L & 8 / 10\end{array}$ & 1 & Enl. blind spot & h loss \\
\hline 18 & $\mathbf{F}$ & 55 & Normal & $\begin{array}{lr}\mathrm{R} & 9 / 10 \\
\mathrm{~L} & 10 / 10\end{array}$ & 2 & $\begin{array}{l}\text { Enl. blind spot } \\
\text { Enl. blind spot }\end{array}$ & $\begin{array}{l}\text { No loss } \\
\text { No loss }\end{array}$ \\
\hline 19 & $\mathbf{M}$ & 57 & Normal & $\begin{array}{l}\mathbf{R} \quad 10 / 10 \\
\mathbf{L} \quad 1 / 10 \\
\text { (amblyopic) }\end{array}$ & $\begin{array}{l}1 \\
1\end{array}$ & $\begin{array}{l}\text { Enl. blind spot } \\
\text { Enl. blind spot }\end{array}$ & $\begin{array}{l}\text { No loss } \\
\mathrm{h} \text { loss }\end{array}$ \\
\hline 20 & $\mathbf{M}$ & 59 & Normal & $\begin{array}{ll}\mathbf{R} & 12 / 10 \\
\mathrm{~L} & 10 / 10\end{array}$ & $\begin{array}{l}2 \\
2\end{array}$ & $\begin{array}{l}\text { Enl. blind spot } \\
\text { Enl. blind spot }\end{array}$ & $\begin{array}{l}\text { No loss } \\
\mathrm{h} \text { loss }\end{array}$ \\
\hline
\end{tabular}

CS function = contrast sensitivity function; $\mathbf{R}=$ right eye; $\mathbf{L}=$ left eye; Enl. blind spot = enlarged blind spot; $\mathbf{n}$ loss $=$ notch contrast sensitivity loss (spatial frequency cycles per degree); 1 loss = low-frequency contrast sensitivity loss; h loss = high-frequency contrast sensitivity loss.

trast loss was observed (octaves). CS function was obtained in 40 eyes. Of the 37 non-amblyopic eyes 16 had abnormal CS function. Generalised loss was seen in three eyes. Losses that could be classified as selective were found in 13 eyes. Of these 13 eyes a notch loss was present in eight eyes. The loss affected selectively the high frequency range (above $3 \cdot 2$ cycles/ degree) in three eyes and the low frequency range (below $3 \cdot 2$ cycles/degree) in two eyes.

Abnormalities of CS function were not related to visual acuity loss. Of the 37 non-amblyopic eyes 16 had CS loss (43\%). Twelve of these 16 eyes had normal visual acuities. Six of the eight eyes with notch defects had a normal acuity. Of the three eyes with high frequency loss two had normal visual acuities, and of the two eyes with low frequency loss none had acuity loss attributed to BIH. Two of the three eyes with generalised loss had normal visual acuities.

Two of the three patients with impaired acuity not related to BIH (amblyopia) showed CS loss. One patient had low frequency loss with a vision of $7 / 10$, and the other showed high frequency loss with a visual acuity of $1 / 10$. The third patient with unilateral amblyopia (acuity 9/10) had a normal CS curve of the affected eye.

Six eyes (16\%) had acuity impairment at 
Table 2 Follow-up results of neuro-ophthalmological investigations in 11 BIH patients (key to symbols as in table 1)

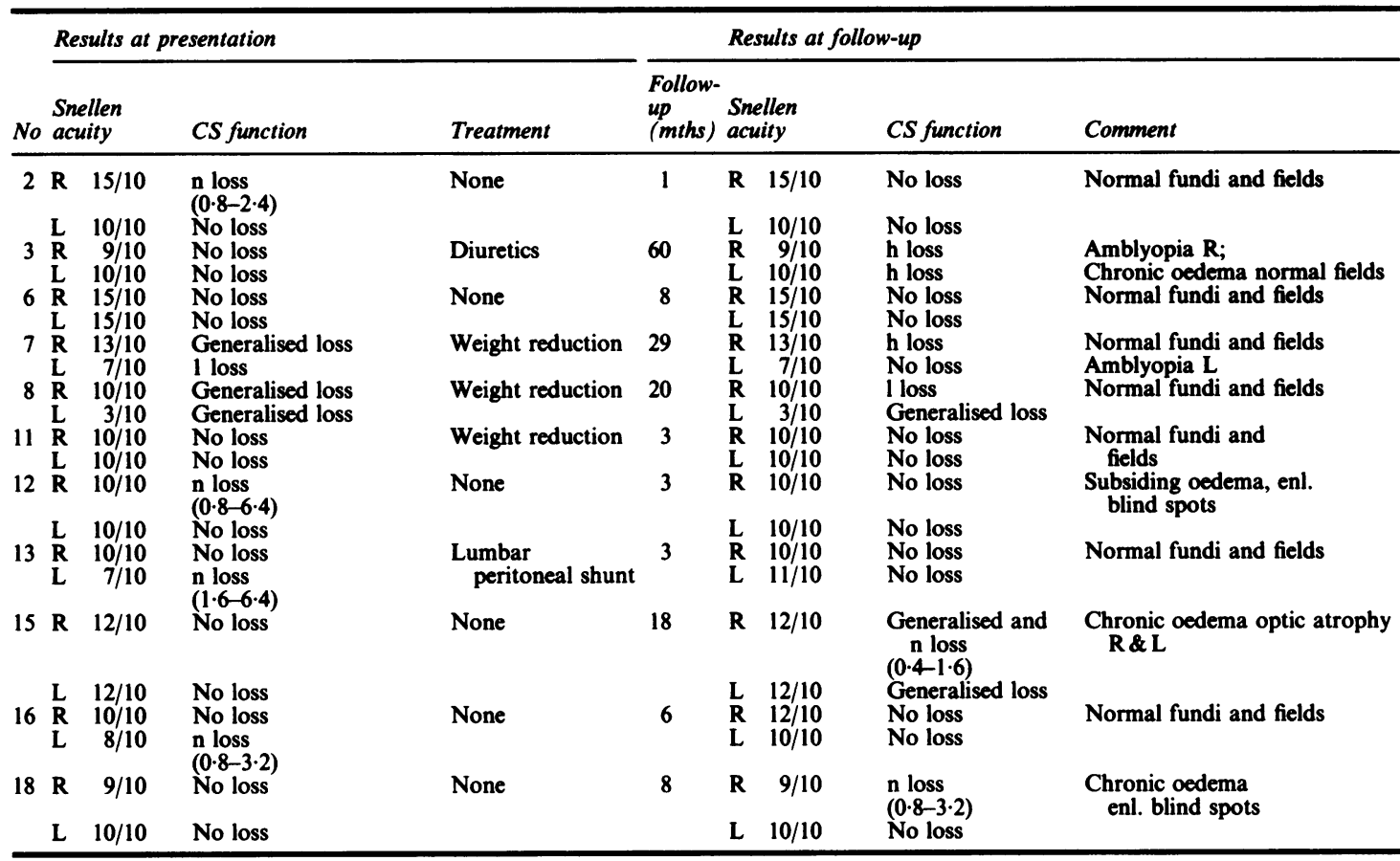

presentation, attributed to BIH. Only two eyes with slight acuity impairment $(9 / 10)$ had normal CS functions. The remaining four eyes with acuity impairment had diverse type of CS loss (generalised, notch and high frequency loss).

Transient visual obscurations were an initial symptom in four patients. Three of these had unilateral visual acuity impairment at presentation. Blurred vision with normal visual acuity was an initial complaint in five patients. All these nine patients had abnormal CS functions (12 eyes). The results of neuro-ophthalmological investigations of all 20 patients are listed in table 1.

Eleven patients had repeated CS measurements after one to 60 months. The results of the follow-up investigations of these 11 patients are listed in table 2. Six patients had a normal CS function for both eyes at follow-up, they all had restored visual acuities. Figure 2a shows the changes of serially CS measurements in patient 2 . Initially there was a unilateral notch loss centred at 1.6 cycles/degree (right eye). Two weeks later notch losses centred at the same spatial frequency were observed in both eyes. Another 2 weeks later, after papilloedema had disappeared, CS losses had completely resolved. Of this group of patients with normal CS function at follow-up one had developed optic disc pallor and another still had subsiding papilloedema in spite of normal acuities.
Five patients had abnormal CS functions. One patient (no. 3) had developed high frequency loss in both eyes without visual acuity deterioration. She had bilateral papilloedema of one dioptre for 60 months. Patient no. 7 (fig 2b) had good improvement of CS function for both eyes except for high frequency loss in the right eye. During her illness of 3 years, visual acuity scores had not changed and her visual fields had become normal. Patient no. 8 (fig 2c) had persisting general CS loss in the left eye with marked degree of acuity loss $(3 / 10)$, which was unchanged after 20 months. CS function of the right eye had ameliorated and only low frequency loss was present at follow-up. Patient no. 15 (fig 2d) illustrates progressive CS loss for both eyes during 18 months follow-up without any change of visual acuities or visual fields. Patient no. 18 with normal CS functions and unilateral acuity impairment developed a notch defect without any acuity deterioration.

\section{Discussion}

Spatial CS function, in 20 BIH patients, elicited by sinewave gratings, was abnormal in 16 of the 37 nonamblyopic eyes. Six eyes had Snellen acuity impairment attributed to BIH. Only four of the 16 eyes with abnormal CS function had also acuity loss. Only two eyes with slight visual acuity impairment 

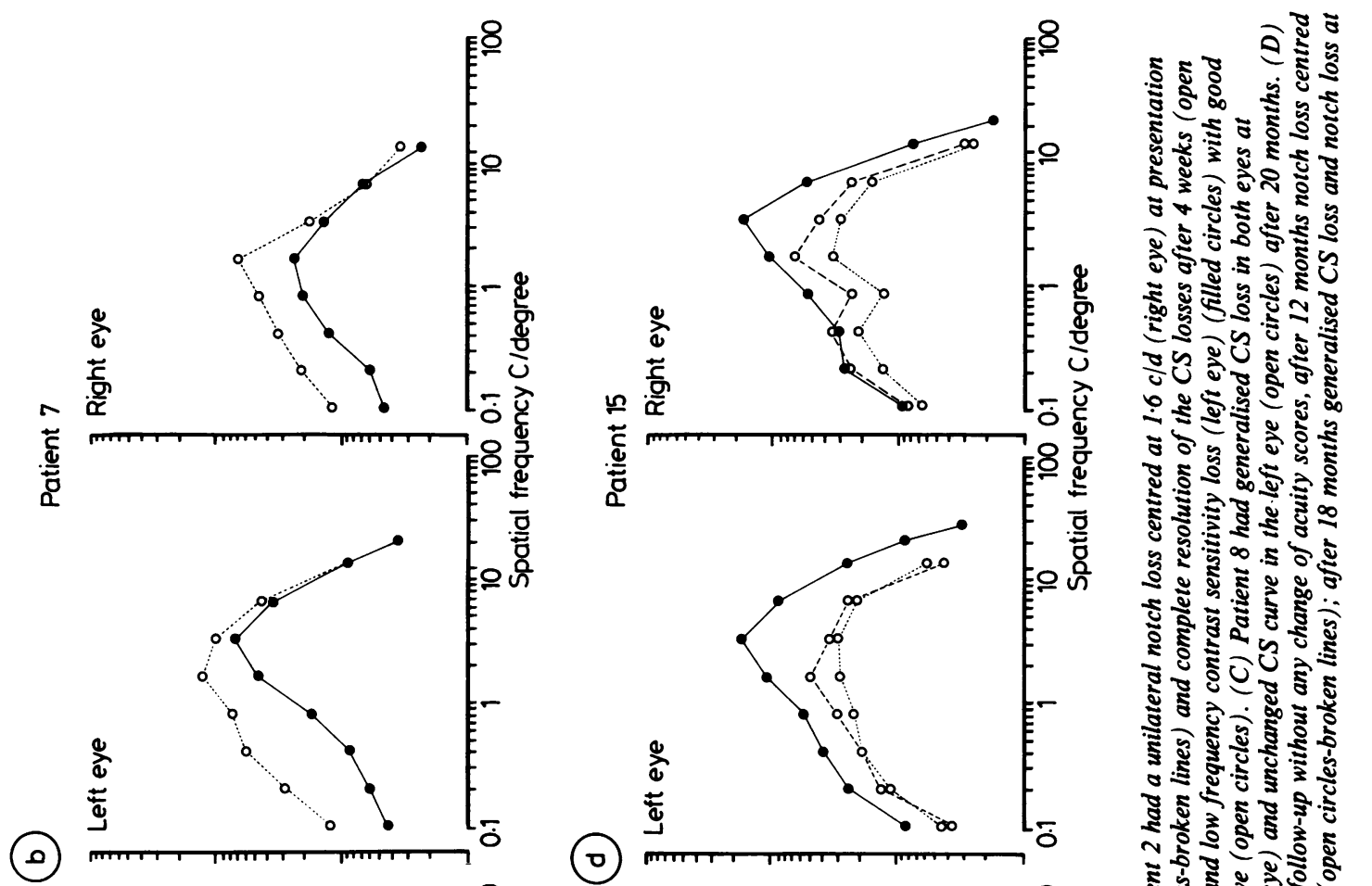

ำ

จ

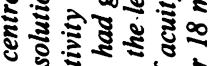

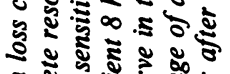

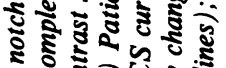

จ

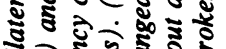

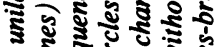

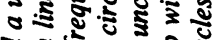

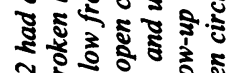

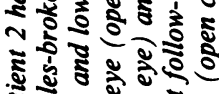

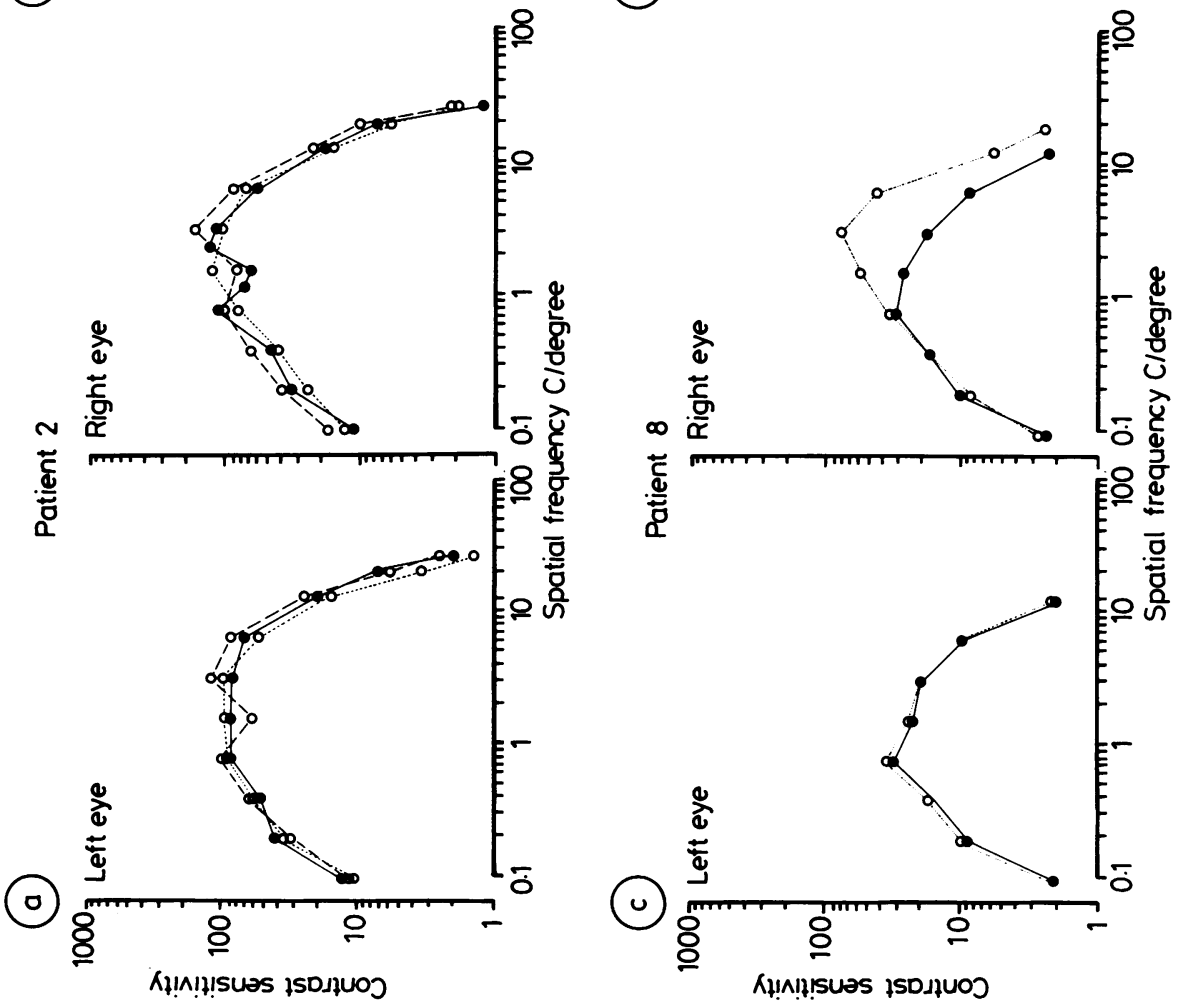

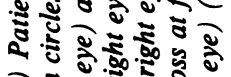

₹

$\therefore$ 济

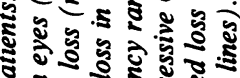

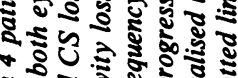
- + .

ปับ

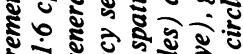

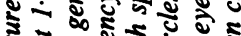
รู่ 곯 ปั ฝั

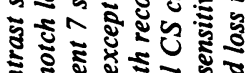

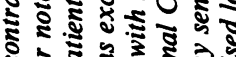

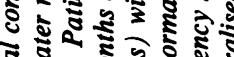

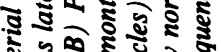

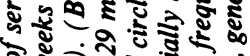

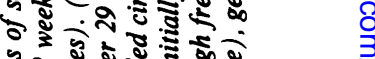

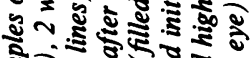

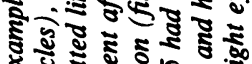

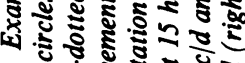

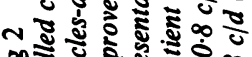

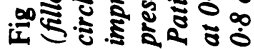


attributed to BIH had normal CS function. In one of these two, a notch defect later developed during follow-up, without deterioration of visual acuity. CS measurement was, therefore, superior in detecting visual loss in comparison with the Snellen acuity tests.

Our data confirm one earlier report of abnormal visuospatial CS function in BIH. Wall ${ }^{15}$ found CS loss in 13 of 24 eyes of BIH patients. Unfortunately, his results are based on the Arden grating test. ${ }^{16}$ This method generates substantial intrasubject variability. Moreover, high spatial frequencies (above 6.4 cycles/degree) cannot be tested with this method.

Visual obscurations and blurred vision are the most frequent visual symptoms in $\mathrm{BIH} .{ }^{1-7}$ In this study there was a close relationship between the presence of these visual symptoms and CS abnormality. All 11 patients with blurred vision or visual obscurations had abnormal CS functions. Six of these 11 patients had normal visual acuities at presentation. Seven of the nine patients with normal subjective vision had also normal CS curves for both eyes. One patient had unilateral high frequency CS loss with normal visual acuity and another patient had also high frequency CS loss in one eye with impaired visual acuity due to amblyopia since childhood. The CS loss of this patient probably was not related to BIH.

Although there was no unitary type of CS loss in our patient group, the most frequent type of deficit, observed in eight eyes, was a notch defect. These intermediate spatial frequency losses affected the middle-frequency region preferentially. These CS losses are not unique to papilloedema. Results similar to those described here have also been reported in conditions ranging from optic neuritis ${ }^{1718}$ and cortical lesions ${ }^{19}$ to Parkinson's disease. ${ }^{2021}$ Spatial frequency selectivity is attributed to cortical neurons and not to neurons of the retina or geniculate body. ${ }^{122}$ Peripheral damage, however, can also in some degree selectively degrade CS. It has been suggested that the retinal image is encoded by the ratio of activity in neuronal populations responsive to different spatial frequencies. ${ }^{2324}$ A neural deficit that distorts the sensitivity of these harmonic analysers may impair spatial processing. Sinewave gratings effectively stimulate populations of neurons responsive to only limited bands of spatial frequency. In papilloedema, neural deficit may result in depression of CS restricted to intermediate spatial frequencies.

When field defects and enlarged blind spots encroach upon the region of the field tested, CS loss may occur as a result of these field defects. In a simulation study Hess and Plant ${ }^{25}$ demonstrated that various types of CS loss can be modelled by different types of visual field loss. A deficit maximal in the centre of the visual field affected high spatial fre- quencies, parafoveal deficit caused medium spatial frequency loss, and peripheral deficit gave rise to low frequency loss. Visual field defects encountered in our patient group are given in table 1. An enlarged blind spot is the classic defect in BIH and was detected in 31 non amblyopic eyes of 17 patients either as the only visual defect or associated with other disc-related defects. The stimulus field subtended the enlarged blind spots only when CS was measured for low spatial frequencies. For higher spatial frequencies $(0.8$ to 25.6 cycles/degree) the enlarged blind spot did not encroach upon the field tested, bound with the relative small stimulus field at $200 \mathrm{~cm}\left(8.5^{\circ}\right.$ by $\left.6.0^{\circ}\right)$. The generalised losses ( 3 eyes), high frequency losses ( 3 eyes) and notch defects in the frequency range above 0.8 cycles/degree ( 4 eyes) could therefore not have been accounted for by the enlarged blind spot. Some effect of the enlarged blind spot in generating the intermediate spatial frequency losses below 0.8 cycles/degree ( 3 eyes) cannot be excluded. Two of the three eyes showing nasal field defects, had normal CS function; the remaining eye had a 2 octaves wide CS loss centred at 1.6 cycles/degree. Only one patient (no. 5 ) had marked field defects. It is well known that the thresholds for gratings are significantly raised if less than 4 cycles of the gratings are visible. ${ }^{12-14}$ In this patient the low frequency CS loss in both eyes could be considered, therefore, as a result of the severe concentric field constriction. It seemed unlikely that the cecocentral scotoma in the left eye of patient no. 13 could account for the 2 octaves wide notch loss centred at $3 \cdot 2$ cycles/degree, because CS for higher spatial frequencies were unaffected. The vast majority of CS deficits encountered in our patient group could not be explained by the visual field abnormalities.

The clinical application of CS measurement in monitoring the progression or regression of BIH is well illustrated by the serial measurements in 11 patients with BIH. Progressive visual loss in longstanding papilloedema and important improvement of visual function in subsiding papilloedema can occur without any change in Snellen acuity or visual field charting. In our limited follow-up study important visual acuity deterioration was not observed; even progressive CS loss did not predict subsequent visual acuity loss.

Although some factors such as systemic hypertension, raised intraocular pressure, choroidal folds with subretinal neovascularisation may predispose to severe loss of acuity, ${ }^{17}$ general outcome in BIH cannot be predicted reliably. Visual acuity loss can occur at presentation or late during the course of the disease. Blurred vision and visual obscurations do not necessarily predict subsequent visual acuity loss. Visual field abnormalities, including nasal field defects and concentric constrictions have not proved to deter- 
mine long-term prognosis for visual acuity. Even optic atrophy is not always accompanied by acuity loss or field defects. A more extensive, prospective study of BIH with sequential measurements of CS, visual fields and visual evoked potentials is warranted to reliably demonstrate warning signs of impending visual failure.

The authors are grateful to Professor $\mathbf{H}$ van Crevel, Department of Neurology, Academisch Medisch Centrum, Amsterdam, for his critical and stimulating comments.

\section{References}

1 Corbett JJ, Savino PJ, Thomson HS, et al. Visual loss in pseudotumour cerebri. Arch Neurol 1982;39:461-74.

2 Bulens C, De Vries WAEJ, Van Crevel H. Benign intracranial hypertension. A retrospective and follow-up study. J Neurol Sci 1979:40:147-57.

3 Boddie HG, Banna M, Bradley WG. "Benign" intracranial hypertension. A survey of the clinical and radiological features, and long term prognosis. Brain 1974;97:313-26.

4 Johnston I, Paterson A. Benign intracranial hypertension, Part I (diagnosis and prognosis). Brain 1974;97:289-300.

5 Weisberg LA. The syndrome of increased intracranial pressure without localizing signs: a reappraisal. Neurology 1975; 25:85-8.

6 Rush JA. Pseudotumor cerebri. Clinical profile and visual outcome in 63 patients. Mayo Clin Proc 1980;55:541-6.

7 Orcutt JC, Page NGR, Sanders MD. Factors affecting visual loss in benign intracranial hypertension. Ophthalmology 1984;91: 1303-12.

8 Cogan DG. In: Cogan DG ed. Neurology of the Visual System. Springfield, Ill: Charles C Thomas Publisher, 1966:145.

9 Walsh FB, Hoyt WF. In: Walsh FB, Hoyt WF, eds. Clinical Neuro-ophthalmology, ed 3. Baltimore: Williams \& Wilkins Co, 1969:576.

10 Bodis-Wollner I, Casima JM. Contrast sensitivity measurement in clinical diagnosis. In: Lessel S, Van Dalen JTW, eds. Neuroophthalmology. Amsterdam: Exerpta Medica, 1980:373-401.

11 Bulens C, Meerwaldt JD, Van der Wildt GJ. Effect of stimulus orientation on contrast sensitivity in Parkinson's disease. Neurology 1988;38:76-81.

12 Campbell FW, Robson JG. Application of Fourier analysis to the visibility of gratings. J Physiol (Lond) 1968;197:551-66.

13 Savoy RL, MacCann JJ. Visibility of low-spatial frequency sine wave targets: dependence on number of cycles. J Opt Soc Am 1975;65:343-50.

14 Van der Wildt GJ, Keemink CJ, Van den Brink G. Gradient detections and contrast transfer by the human eye. Vision Res 1976;16:1047-53.

15 Wall $M$. Contrast sensitivity testing in Pseudotumor cerebri. Ophthalmology 1986;93:4-7.

16 Arden GB. The importance of measuring contrast sensitivity in cases of visual disturbances. Br J Ophthalmol 1978;62:198-209.

17 Zimmern RL, Campbell FW, Wilkinson IMS. Subtle disturbances of vision after optic neuritis elicited by studying contrast sensitivity. J Neurol Neurosurg Psychiatry 1979; 42:407-12.

18 Medjbeur S, Tulunay-Keesey U. Spatiotemporal responses of the visual system in demyelinating diseases. Brain 1985;108: 123-38.

19 Bodis-Wollner I, Diamond SP. The measurement of spatial contrast sensitivity in cases of blurred vision associated with cerebral lesions. Brain 1976;99:695-710.

20 Bulens C, Meerwaldt JD, Van der Wildt GJ, et al. Contrast sensitivity in patients with Parkinson's disease. Neurology 1986;36:1121-5.

21 Regan D, Maxner C. Orientation-selective visual loss in patients with Parkinson's disease. Brain 1987;110:415-32.

22 Regan D. Visual information channeling in normal and disordered vision. Psychol Rev 1982;89:407-44.

23 Pollen DA, Lee JR, Taylor JH. How does the striate cortex begin the reconstruction of the visual word. Science 1971;173:74-7.

24 Maffei L, Fiorentini A. The visual cortex as a spatial frequency analyser. Vision Res 1973;13:1255-67.

25 Hess RF, Plant GT. The electrophysiological assessment of optic neuritis. In: Hess RF, Plant GT, eds. Optic Neuritis. Cambridge: Cambridge University Press, 1986:192-229. 